\title{
Coupling between financing and innovation in a startup: embedded in networks with investors and researchers
}

\author{
Daojuan Wang ${ }^{1}$ (D) $\cdot$ Thomas Schøtt $^{2}$ (D)
}

Published online: 25 June 2020

(C) Springer Science+Business Media, LLC, part of Springer Nature 2020

\begin{abstract}
Innovation may be a basis for starting a business, and financing is typically needed for starting. Innovation and financing may conceivably be negatively related, or be unrelated, or plausibly be beneficially related. These possible scenarios frame the questions: What is the coupling between innovation and financing at inception, and what is the embeddedness of coupling in networks around the entrepreneur, specifically networks with investors and researchers? These questions are addressed with a globally representative sample of entrepreneurs interviewed at inception of their business. Innovation and financing are found to be decoupled, typically; less frequently to be loosely coupled, and rarely to be tightly coupled. Coupling is promoted by networking with both investors and researchers, with additive effects and with a synergy effect. By ascertaining coupling and its embeddedness in networks as a way for building capability in a startup, the study contributes to empirically supported theorizing about capability building.
\end{abstract}

Keywords Startups $\cdot$ Coupling $\cdot$ Financing $\cdot$ Innovation $\cdot$ Networks

Daojuan Wang

daw@business.aau.dk

Thomas Schøtt

tsc@sam.sdu.dk

1 Department of Business and Management, Aalborg University, Fibigerstræde 11, 9220 Aalborg East, Denmark

2 Department of Entrepreneurship and Relationship Management, University of Southern Denmark, Kolding, Denmark 


\section{Introduction}

Innovation may be the basis for starting a business. An entrepreneur may innovate something that is novel to some potential customers, or may use a technique that has not been used earlier, or may be doing something that only few other businesses are doing. In these ways, innovation may be a foundation for the startup. Much scholarship studies innovation. A stream of research focuses on innovation as a basis for starting a business (e.g. Weiblen and Chesbrough 2015; Colombelli et al. 2016; Colombelli and Quatraro 2017).

Financing may be needed for starting. Indeed, typically, a startup requires some financing. An entrepreneur may need little financing, but occasionally requires much financing. Typically, an entrepreneur has some funds of their own for investing in the startup. Frequently, an entrepreneur also requires some funding from other sources, such as family and friends. An entrepreneur often borrows from a loan organization, and sometimes obtains venture capital. A stream of research focuses on financing of startups (e.g. Van Osnabrugge and Robinson 2000; Hsu 2004; Mason and Stark 2004; Croce et al. 2017). Innovation and financing may be unrelated in a startup. Innovation may be accomplished before starting a business, or may be completed on a shoestring budget, and in these situations innovation and financing are unrelated. Furthermore, potential investors may shy away from the riskiness of supporting innovation and prefer to invest in routine production, and also in this situation there is no relation between financing and innovation in a startup. In the extreme, if innovation is pursued without financing, and if a copy-cat startup attracts financing, then innovation and financing are even negatively related. Conversely, innovation may require financing and the entrepreneur may obtain it, and an investor may prefer to finance an innovative rather than a routine startup. In such a situation, innovation and financing will go hand in hand and be coupled beneficially. These scenarios - a negative coupling between innovation and financing, or no coupling between them, or a beneficial coupling between them - represent a gap in our understanding of startups.

This gap frames our first question for research: What is the coupling between innovation and financing at inception?

A second issue is the sources of their coupling. An entrepreneur has networks that channel, enable and constrain the endeavor. An entrepreneur may seek financing by networking with formal and informal investors. An entrepreneur may pursue innovation by networking with researchers and inventors. And an entrepreneur may couple financing and innovation by networking with both investors and researchers. Investors and researchers are not substitutable partners. Rather, investors and researchers provide complementary resources, and there may even be a synergy between their inputs into a startup. Such embeddedness of coupling is another gap in our understanding of new ventures.

This gap frames our second question: What is the embeddedness of coupling in the networks around an entrepreneur, specifically the networks with investors and researchers?

By addressing these two gaps in understanding a startup, this study makes several specific contributions. First, coupling of innovation and financing at inception is a way of building capability in the new business, and the study thus contributes to our understanding of capability building. Second, this study fills a gap by investigating 
whether and how these two important elements - innovation and financing - are channeled, enabled and constrained by different networks - especially networks with the investors and researchers - around the entrepreneur. Third, by focusing on the business founding stage, we overcome the methodological problems caused by hindsight bias, memory decay, and survivorship bias, which pervade retrospective studies.

The following first reviews the theoretical background as a basis for developing hypotheses, then describes the research design, reports analyses, and concludes by relating findings to the literature of entrepreneurship, venture capital and investment.

\section{Theoretical background and hypotheses}

The phenomenon of financing and innovation being interrelated is conceptualized as a coupling. The concept of coupling is classical in studies of organizations (Weick 1976; Orton and Weick 1990). Elements of an organization have a coupling, in that they tend to occur together and to be connected, intertwined, reciprocal, reinforcing, and mutually sustaining within the organization. The coupling has strength; it may be loose, in that the elements are rather independent of one another, or it may be tight, in that the elements are highly interdependent. Loose coupling is often found in an educational organization, whereas tight coupling is more frequent in a firm (ibid.).

Here we apply the concept of coupling to the intertwining between two elements of a startup: financing and innovation. Coupling is tight if the startup is financing and innovating simultaneously. Coupling is loose if the startup is pursuing one of the two, but hardly the other. The elements may be termed decoupled if the startup is pursuing one of the two, but not the other at all. Finally, of course, a startup may be without ambition of any kind; not pursuing any of the endeavors.

An established business may benefit from self-reinforcing dynamics between innovation and financing. Accomplished innovation may attract investors, and, reciprocally, financing is a means for innovation. For a nascent entrepreneur, however, the dynamics between financing and innovation are quite different. The entrepreneur is in the process of starting. There cannot yet be any reciprocal interaction between market feedback and the entrepreneur's learning and capability development. No market returns from sales can be employed to strengthen innovation capability. Moreover, the business opportunity pursued by the entrepreneur is still up for evaluation and modification; the business is still an idea.

Nevertheless, at this formative stage, there are interactions between the entrepreneur and stakeholders, e.g., potential investors, inventors, and incubators. Through this interaction, the entrepreneur modifies ideas and visions for the business and anticipates feasibility, outcomes and attractiveness (Lichtenstein et al. 2006). In this realm, the entrepreneur shapes strategic aspirations, and confidence in achieving specific strategic goals.

Ambition for financing and ambition for innovation tend to co-evolve as they build on similar underlying organizational strengths. Hence, we may reasonably expect that in some resource environments around the entrepreneur there will be a presence of ambition for financing and simultaneously also ambition for innovation. Moreover, it is reasonable to theorize that the more the entrepreneur is exposed to such environments, the more likely the entrepreneur's aspirations are to include elements of financing and 
innovation. This external influence on the entrepreneur's aspiration formation processes is represented by Ansoff (1987) in his model of paradigmatic complexity of the strategy formation process. At a more general level, it is also represented in Ajzen's model of planned behavior, in which stakeholders' resources, norms and expectations shape the entrepreneur's intentions, goals and aspirations (Liñán and Chen 2009).

A similar prediction can be made from social comparison theory (Boyd and Vozikis 1994). Because the entrepreneur's business is not yet tested in the market, the entrepreneur may rely on modeling and imitation as a source of self-efficacy. In this process beliefs in own capabilities, and thereby aspirations, will be assessed by successes and failures of similar others (Wood and Bandura 1989). Finally, the entrepreneur's aspirations may be influenced by persuasion through encouragement, even in situations where encouragement is given on unrealistic grounds (ibid.). These mechanisms may work through direct relationships held by the entrepreneur or indirectly as the entrepreneur observes and interprets stimuli from the wider environment.

Coupling may be pursued as a strategy. As a strategy it may be partly based on an analysis of strengths, weaknesses, opportunities and threats, SWOT, as business students learn and managers and owners apply. An entrepreneur can hardly estimate any of the elements with reasonable validity and reliability. But the entrepreneur is likely to discuss such matters with others, listen to them, and take their advice into consideration when pursuing financing and innovation. Thus the coupling is likely to be influenced by the network around the entrepreneur, the network of people giving the entrepreneur advice on the new business. As suggested by literature on entrepreneurial opportunity and alertness, it is a social process to create and grow a new venture, entailing efforts by entrepreneurs to use their networks to mobilize and deploy resources to exploit an identified opportunity and achieve the success (Ebbers 2014; Adomako et al. 2018). Besides, "an important part of the nascent entrepreneurial process is a continuing evaluation of the opportunity, resulting in learning and changes in beliefs" (McCann and Vroom 2015). The pursuit of coupling is thus embedded in the advice network, which channels, enables and constrains beliefs and strategy, specifically pursuit of coupling of financing and innovation.

The people giving advice to the entrepreneur are often drawn from a wide spectrum, both from the private sphere of family and friends and from the public sphere comprising the work-place, the professions, the market and the international environment (Jensen and Schøtt 2017). An entrepreneur's networking in the private sphere and networking in the public sphere differ in their consequences for the startup. Networking in the public sphere promotes, whereas networking in the private sphere impedes, such business endeavors as innovation, exporting and expectations for growth (Schøtt and Sedaghat 2014; Ashourizadeh and Schøtt 2015; Schøtt and Cheraghi 2015). We here consider how such networking influences coupling of financing and innovation.

\section{Private sphere network constraining coupling}

An entrepreneur's networking in the private sphere of family and friends may shape the coupling between innovation and financing through its influence on ambition of the entrepreneur. The entrepreneur's family is often putting its wealth at risk in the startup, and is likely to be cautious and to caution the entrepreneur against being overly selfefficacious, overly optimistic about business opportunities, and overly risk-willing. 
Furthermore, due to mutual trust, frequent contacts, intimacy and reciprocal commitments in such relationships (Granovetter 1973, 1985; Greve 1995; Anderson et al. 2005), their influence tends to be deep and significant.

When private sphere networking constrains the entrepreneurial mindset, the entrepreneur becomes less ambitious and will pursue less financing or less innovation, and will be especially reluctant to pursue financing for innovation.

Conversely, an entrepreneur without such a constraining network in the private sphere will plausibly feel rather free, and will more wishfully think of own capability, of own efficacy, of opportunities, and of risks, and consequently will be more ambitious and therefore also pursue both financing and innovation.

Family members and friends tend to move within the same circles with the entrepreneur (Anderson et al. 2005). They know each other and are likely to have high degree of social, cultural, educational and professional homophily (Granovetter 1973, 1985; Greve 1995). The members within such network are likely to possess or access much overlapping information and multiple redundant ties therefore often add little value when an entrepreneur is seeking novel resources/information and financing.

The consideration concerning the private sphere leads us to hypothesize,

Hypothesis 1: Networking within the private sphere reduces coupling between financing and innovation.

\section{Public sphere networking shaping coupling}

An entrepreneur's networking for advice in the public sphere is drawn from the workplace, professions, market and the international environment. These formal and informal advisors are mostly business people and business-related people. They are likely to be more self-efficacious, optimistic about opportunities, and risk-willing, than the entrepreneur's private sphere network. They are likely to influence the entrepreneur to be more self-efficacious, optimistic and risk-willing, and thereby more ambitious and more likely to pursue both financing and innovation.

Apart from such positive mindset influence, a diverse set of persons working in different public contexts with quite different knowledge bases, experiences, mental patterns, and associations enable the entrepreneur to access to a broad array of nonredundant novel ideas and expanded financing opportunities (Hsu 2005; Burt 2004; Dyer et al. 2008). Particularly, some critical contacts in the public sphere, such as venture capitalists, successful entrepreneurs, and business incubators, not only directly bring the nascent entrepreneur valuable suggestions, creative ideas, and financial resources simultaneously, but also play the role of business referrals and endorsements and further broaden the entrepreneur's opportunities for acquiring and enhancing innovation and financing capabilities (Van Osnabrugge and Robinson 2000; Mason and Stark 2004; Löfsten and Lindelöf 2005; Cooper and Park 2008; Ramos-Rodríguez et al. 2010; Croce et al. 2017), generating a "snowballing effect". These arguments thus lead us to specify,

Hypothesis 2: Networking in the public sphere promotes coupling between financing and innovation. 


\section{Networking with potential investors promoting coupling}

Investors, especially venture capitalists and angel investors, often appreciate and encourage innovation with financial support (Kortum and Lerner 2000; Engel and Keilbach 2007; Bertoni et al. 2010). Investors frequently bring the entrepreneurs more than purely financial capital, such as their technical expertise, market knowledge, customer resources, strategic advices, and network augmentation (Sapienza and De Clercq 2000; Mason and Stark 2004; Brown et al. 2018). Investors, angel investors and VCs like to syndicate their investments with others, and to share the investment risk and strengthen evaluating and monitoring capacities (Kaplan and Strömberg 2004; Wong et al. 2009; Brown et al. 2018), which will expand and strengthen their financial and innovation support. As observed by Brown et al. (2018), a key feature of the entrepreneurs who use equity crowdfunding is their willingness to innovate and they are very proficient at combining financial resources from different sources and drawing on the networks to alleviate and overcome their internal resource constraints. Therefore, networking with these investors is likely to spur and enable the entrepreneur in risktaking and innovative behavior.

Meanwhile, being in the investors' circle, the entrepreneur is easily identified and accessed. In the networking process, the actors learn more about each other, trust emerges from repeated interactions, and then stimulates closer interpersonal interaction and mitigates the fear of opportunistic behaviors caused by information asymmetry (Jensen and Meckling 1976; De Bettignies and Brander 2007). Moreover, the endorsement by reputable investors can send a favorable signal to the investment market about the entrepreneur and the project, and attract more investors to join (see ZIP case by Steier and Greenwood 2000). Especially, as found by Van Osnabrugge and Robinson (2000), angel investors often have entrepreneurial and business operation experience, and have empathy for an innovative entrepreneur, and have the passion to help, and perform less due diligence but invest more by instincts. Altogether, this may enhance the matching opportunity between innovative ideas and funding needs and investment desire, leading to a coupling between innovation and financing. Therefore, we hypothesize,

Hypothesis 3: Networking with potential investors promotes coupling between financing and innovation.

\section{Networking with researchers and inventors promoting coupling}

Timmons and Bygrave (1986, p.170) identified a shared view between founders of innovative ventures and venture capitalists that "the roots of new technological opportunities depend upon a continuing flow of knowledge from basic research". Thus researchers and inventors are generators and carriers of knowledge, intellectual property, and patents. By networking with them, the entrepreneur may acquire these innovative resources. Codified and tacit knowledge is transferred in different ways, notably through education, consulting, and R\&D-based project cooperation, and conversations. 
Indeed, the benefits of networking with researchers or inventors is expressed in arrangements in innovation systems, such as the Triple Helix model (Etzkowitz 2003); science parks (Löfsten and Lindelöf 2005), entrepreneurial universities, incubators, research-based spin-offs, open innovation (Etzkowitz 2003; Rothaermel et al. 2007; Enkel et al. 2009), and industrial Ph.D. projects. These models, polices, organizational formats and education programs are proposed with the same strategic intention: to provide a nurturing environment, and link talent, technology, capital and know-how to spur innovation and commercialization of technology.

Networking with researchers and inventors not only enables the entrepreneur to tap into a broader research community, but may also sends a signal to the market about the quality and veracity of the project and its knowledge foundation, and may reduce the investors' worries about their investment (Hsu 2004; Murray 2004), especially for an early-stage entrepreneur without established reputation and performance record, and particularly when the venture is innovative. Therefore, we propose:

\section{Hypothesis 4:Networking with researchers promotes coupling between financing and innovation.}

\section{Networking with both investors and researchers reinforcing coupling}

Networking with both investors and researchers can generate synergy leading to further coupling of innovation and financing as elaborated in the following.

As argued above, networking with investors and with researchers or inventors separately can provide the entrepreneur with both financial resources, knowledge and talents for innovation. When the entrepreneur networks with both investors and researchers, the resources obtained from the two parties may generate an additional "positive loop effect", which means more sophisticated innovation brought by the ties with researchers and inventors attract more capital, and more capital available for $R \& D$ further enhance innovation aspiration, which again attract more capital and then more R\&D investment, and then enhance innovation; in mutual reinforcement.

Moreover, networking with both an investor and a researcher, implies that when legitimacy is obtained from one of the two, this sends a signal to the other encouraging the other to bestow legitimacy on the entrepreneur, which may attract further financing and ideas for innovation. We may call this a "reinforced signaling effect". The ties with researchers, investors, and their network contacts help open up more relations for acquiring additional funds and knowledge like "reinforced snowball effect". Timmons and Bygrave (1986) had observed that there were geographical oases for incubating a bulk of innovative technological ventures, where the founders, entrepreneurs, technologists, and investors cluster. Using a longitudinal case study, Calia et al. (2007) illustrate how a technological innovation network (with the involvement of universities, venture investors, and banks) enables a case company to establish its business and to survive and grow. These synergies suggest an effect that is over and above the two separate effects of networking with investors and networking with researchers, 
Hypothesis 5: Networking with both investors and researchers further enhances coupling between financing and innovation.

The hypothesized effects are illustrated in Fig. 1.

\section{Research design and data}

The world's entrepreneurs are surveyed by the Global Entrepreneurship Monitor (Bosma 2013). In most countries covered in the period 2009 to 2014 the survey included questions about networking, financing and innovation.

\section{Sampling}

GEM samples adults in two stages. The first stage occurs when a country is included, namely when a national team is formed and joins GEM to conduct the survey in its country. Hereby 50 countries were covered where the essential questions were asked. These countries are drawn from a diversity of regions, cultures, economies, and levels of development, and form a sample of countries which is fairly representative of the countries around the world.

The second stage of sampling is the fairly random sampling of adults within a country, and then identifying the starting entrepreneurs. Entrepreneurs at inception are identified as those who are currently trying to start a business, have taken action to start, will own all or part of the business, and have not yet received, or just begun to receive, some kind of compensation. By this identification of entrepreneurs, this sample is 10,582 entrepreneurs who reported their networking, financing, and innovation. Representativeness of sampling enables generalization to the world's starting entrepreneurs and their startups.

\section{Measurements}

\section{Financing}

Financing of the startup was measured by asking the entrepreneur,

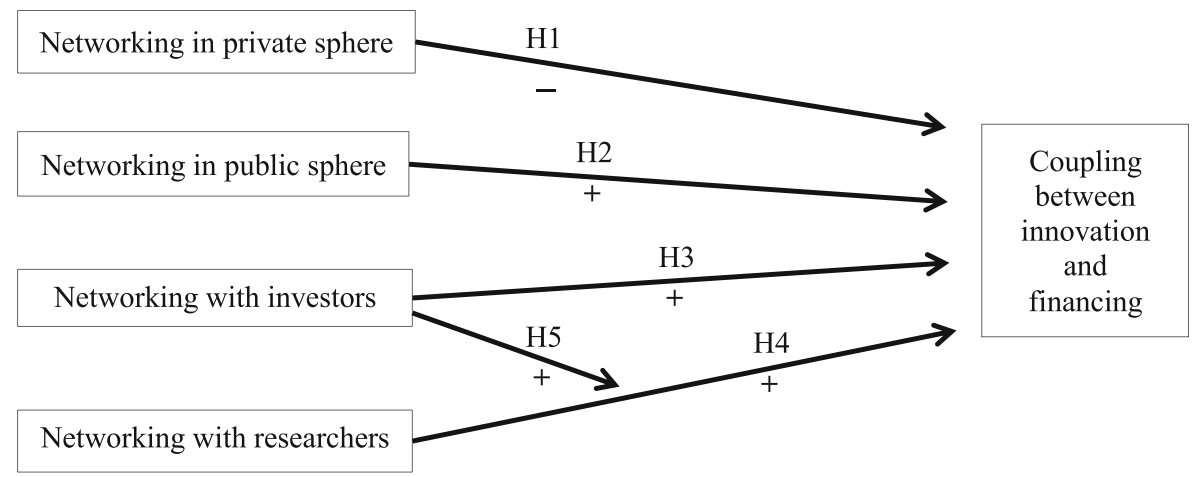

Fig. 1 Hypothesized effects on coupling 
How much money, in total, will be required to start this new business? Please include both loans and equity/ownership investments.

The amount is recorded in the local currency, an amount from 0 upward. To make this comparable across countries, the amount is normalized by dividing by the median for the country's responding entrepreneurs. Then, to reduce the skew, we take the logarithm (first adding 1), a measure that runs from 0 for no financing, and then upward. This indicator of financing enters into the measurement of coupling.

\section{Innovation}

Innovativeness in the startup was indicated by asking three questions,

Have the technologies or procedures required for this product or service been available for less than a year, or between one to five years, or longer than five years?

Will all, some, or none of your potential customers consider this product or service new and unfamiliar?

Right now, are there many, few, or no other businesses offering the same products or services to your potential customers?

The answer to each question is here coded $0,1,2$ for increasing innovativeness. The three measures are inter-correlated positively. The three measures are averaged as an index of innovation, running from 0 to 2 . This index of innovation enters into the measurement of coupling.

\section{Coupling between innovation and financing}

Two business practices, here innovation and financing, are coupled in so far as they are pursued jointly. The coupling between two practices in a business is indicated by their co-occurrence at inception of the business. Coupling between innovation and financing is high to the extent that innovation is high and financing is high. Conversely, coupling is low when either of them is low. When the occurrence of each practice is measured on a scale from 0 upward, the coupling of the two practices is indicated by the product of the two measures:

Coupling between financing and innovation $=$ Financing $*$ Innovation

If financing is 0 or if innovation is 0 , then coupling is 0 . Conversely, if both financing is high and innovation is high, then coupling is very high. The scale has no intrinsic meaning, so, for analyses, the measure of coupling is standardized.

Validity can be ascertained. Coupling expectedly correlates positively with expectation for growth, as an indication of performance at inception. Growth-expectation is indicated as expected number of persons working for the business when five years old (transformed logarithmically to reduce skew). The correlation is positive (.26 with $p<.0005)$ confirming validity of the operationalization of coupling. 


\section{Networking}

The network around an entrepreneur is indicated by asking the entrepreneur to report on getting advice,

Various people may give you advice on your new business. Have you received advice from any of the following? Your spouse or life-companion? Your parents? Other family or relatives? Friends? Current work colleagues? A current boss? Somebody in another country? Somebody who has come from abroad? Somebody who is starting a business? Somebody with much business experience? A researcher or inventor? A possible investor? A bank? A lawyer? An accountant? A public advising services for business? A firm that you collaborate with? A firm that you compete with? A supplier? A customer?

Networking in the private sphere is measured as number of advisors among the four: spouse, parent, other family, and friends, a measure going from 0 to 3 . Networking with a researcher or inventor is measured dichotomously, 1 if advised by a researcher or inventor, and 0 if not. Networking with a possible investor is measured dichotomously, likewise, 1 if advised by a possible investor, and 0 if not. The network with others in the public sphere is measured as number of advisors among the other 14, a measure going from 0 to 14 (Jensen and Schøtt 2017).

Validity can be assessed. In the theoretical section we argued that private sphere networking is associated negatively, and public sphere networking is associated positively, with self-efficacy and opportunity-perception. These correlations all turn out to be as expected indicating validity of the operationalization of networks.

\section{Control variables}

The analysis controls for attributes of the entrepreneur and the business. Gender is coded 0 for males and 1 for females. Age is measured in years. Education is indicated in years of schooling. Motive for starting the business is either seeing a business opportunity or necessity to make a living, coded 1 and 0 , respectively. Owners is number of owners, transformed logarithmically to reduce skew. We also control for macro-level context in two respects, national wealth as GNI per capita, and the elaboration of the national entrepreneurial eco-system, measured as the mean of the framework conditions measured by GEM in its National Expert Survey (Bosma 2013).

\section{Technique for analysis}

The population is the world's entrepreneurs, where a respondent is surveyed in a country. The data are thus hierarchical with two levels, individuals nested within countries. The country should be taken into account, both because level of activity, e.g. networking and innovation, differs among countries, and because behavior is similar within each country. These circumstances of country are taken into account in hierarchical linear modeling (Snijders and Bosker 2012). Hierarchical linear modeling is otherwise very similar to linear regression. Notably, the effect of a condition is tested and estimated by a coefficient. Hierarchical linear modeling is used in Table 3. 


\section{Results}

\section{Descriptive statistics}

The sample of 10,582 starting entrepreneurs is described by correlations, Table 1. Furthermore, among the entrepreneurs, 9\% were networking with a researcher or inventor, and $13 \%$ were networking with a potential investor. Although these two kinds of networking are not common, they are not rare. These two kinds of networking tend to go hand in hand, unsurprisingly, and are also correlated with networking with others in the public sphere and networking in the private sphere, but none of these correlations are high.

The correlations among variables of interest and between variables of interest and control variables are mostly weak, indicating that there is no problem of multicollinearity in the analysis.

\section{Coupling between financing and innovation}

Coupling of innovation and financing is high to the extent that innovation is high and financing is high. Conversely, coupling is low when either of them is low. To see whether coupling is typical, we cross-tabulate the startups according to their innovation and their financing, Table 2.

Coupling is high in the startups where both innovation and financing is high, the bold-faced $12 \%$ in Table 2. Conversely, coupling is low in the startups where either innovation or financing is low, the italicized $10+12+9+8+8 \%$. In between, coupling is medium where one is medium and the other is medium or high, the $12+14+15 \%$ in Table 2 .

Table 1 Correlations of variables of interest. $(N=10,582)$

\begin{tabular}{llllll}
\hline & $\begin{array}{c}\text { Coupling } \\
\text { Network } \\
\text { with } \\
\text { investor }\end{array}$ & $\begin{array}{l}\text { Network } \\
\text { with } \\
\text { researcher }\end{array}$ & $\begin{array}{l}\text { Network } \\
\text { in public } \\
\text { sphere }\end{array}$ & $\begin{array}{l}\text { Network in } \\
\text { private } \\
\text { sphere }\end{array}$ \\
\hline Coupling & & & & & \\
Network with investor & .14 & & & & \\
Network with researcher & .12 & .31 & & .34 & \\
Network in public sphere & .13 & .43 & .34 & .09 & -.03 \\
Network in private sphere & .002 & .13 & .10 & .33 & -.04 \\
Gender: male & .12 & .07 & .06 & .09 & .02 \\
Age & .02 & -.03 & -.02 & -.03 & .02 \\
Education & .15 & .07 & .06 & .11 & .10 \\
Motive: opportunity & .10 & .08 & .05 & .02 & 0 \\
Owners & .12 & .09 & .08 & .13 & \\
Gross National Income per capita & .07 & .19 & .06 & 0 & 0 \\
Entrep. framework conditions & .09 & .04 & .01 & 0 & \\
\hline
\end{tabular}

Numerical independent variables are standardized, then centered within country 
Table 2 Startups, by innovation and financing. $(N=10,582)$

\begin{tabular}{llcccc}
\hline & & \multicolumn{2}{c}{ Financing } & & \\
\cline { 3 - 5 } & & Low & Medium & High & Total \\
\hline \multirow{2}{*}{ Innovation } & High & $10 \%$ & $12 \%$ & $\mathbf{1 2 \%}$ & $34 \%$ \\
& Medium & $12 \%$ & $14 \%$ & $15 \%$ & $41 \%$ \\
& Low & $9 \%$ & $8 \%$ & $8 \%$ & $25 \%$ \\
& Total & $31 \%$ & $34 \%$ & $35 \%$ & $100 \%$ \\
\hline
\end{tabular}

The table does not clearly display a tendency for innovation and financing to go hand in hand. Indeed, the correlation between financing and innovation is .06 $(p<.0005)$. Thus there is a weak tendency for innovation and financing to co-occur, a coupling that is loose rather than tight.

\section{Networks affecting coupling}

Coupling is affected by the various kinds of networks around the entrepreneur, we hypothesized. Effects on coupling are estimated in the hierarchical linear model, Table 3.

Hypothesis 1 is that coupling is affected negatively by networking in the private sphere. The effect is tested in the first model in Table 3. This effect is negative, thus supporting Hypothesis 1.

Hypothesis 2 is that coupling is affected positively by networking in the public sphere, with advisors other than investors and researchers. This effect is tested in the first model. The effect is positive, thus supporting Hypothesis 2.

Hypothesis 3 is that coupling is affected positively by networking with potential investors. This effect is positive, thus supporting Hypothesis 3 .

Hypothesis 4 is that coupling is affected positively by networking with researchers. This effect is positive, supporting Hypothesis 4. The effects of investors and of researchers are substantial, and the effects of networking in the public sphere and networking in the private sphere are of notable magnitude.

Hypothesis 5 is that coupling is affected positively by networking with investors together with researchers, as a synergy effect that is in addition to the separate effect of investors and the separate effect of researchers. This is tested by expanding the model by including the interaction term, the product of the dichotomy for networking with investors and the dichotomy of networking with researchers. The effect of the interaction is estimated in the second model in Table 3. The interaction effect is positive, thus supporting Hypothesis 5. The effect is actually of a magnitude that is quite substantial. In short, the five hypotheses are all supported. 
Table 3 Coupling affected by networks

\begin{tabular}{|c|c|c|}
\hline & Main effects & Interaction effect \\
\hline Networking with investors & $.170 * * *$ & $.125 * * *$ \\
\hline Networking with researchers & $.172 * * *$ & $.144 * * *$ \\
\hline Networking with both investors and researchers & & $.119 *$ \\
\hline Public sphere networking & $.074 * * *$ & $.074 * * *$ \\
\hline Private sphere networking & $-.040 * * *$ & $-.039 * * *$ \\
\hline Gender: male & $.175 * * *$ & $.175 * * *$ \\
\hline Age & $.047 * * *$ & $.047 * * *$ \\
\hline Education & $.131 * * *$ & $.131 * * *$ \\
\hline Motive: opportunity & $.143 * * *$ & $.143 * * *$ \\
\hline Owners & $.086 * * *$ & $.087 * * *$ \\
\hline Gross National Income per capita & .004 & .004 \\
\hline Entrepreneurial framework conditions & $.067 *$ & $.067 *$ \\
\hline Intercept & $-.217 * * *$ & $-.215 * * *$ \\
\hline \multirow{3}{*}{$\begin{array}{l}\mathrm{N} \text { countries } \\
\mathrm{N} \text { startups }\end{array}$} & Yes & Yes \\
\hline & 50 & 50 \\
\hline & 10,582 & 10,582 \\
\hline
\end{tabular}

Hierarchical linear modeling with random effects of country

Dependent variable is standardized

Independent numerical variables are standardized, then centered within country

Independent dichotomous variables are $0-1$ dummies

$* p<.05 * * p<.01 * * * p<.001$

\section{Discussion and conclusions}

The analyses have addressed the two research questions. What is the coupling between innovation and financing at inception? What is the embeddedness of coupling in the networks around the entrepreneur, specifically the networks with investors and researchers?

The questions have been addressed by a survey of a globally representative sample of entrepreneurs at inception of their startup. The representativeness of sampling implies that findings can be generalized to the world's starting entrepreneurs.

The next sections discuss our findings concerning, first, coupling as a phenomenon, and, second, embeddedness of coupling in networks.

\section{Coupling}

Coupling as a phenomenon was found to be infrequent, in that a typical startup does not pursue both financing and innovation. Often, a startup is either innovative or well financed. Rather few startups are both highly innovative and well financed. Across startups, innovativeness and financing are positively correlated, but only weakly, 
indicating that innovation and financing have a coupling that is loose rather than tight (section 4.2).

Coupling between innovation and financing is a capability. Pursuing such coupling in a startup is building an organizational capability. Coupling goes beyond the capability to innovate and goes beyond the capability to finance starting.

Coupling is a competitive advantage in the competition among startups, a competition to enter the market, survive, expand and grow. Coupling in a startup correlates positively with expectation to grow (section 3.2.3), indicating the benefit to be expected from coupling, and thus indicating that coupling is a competitive advantage.

It is theoretically surprising to find that coupling is so loose, when coupling is a competitive advantage. But empirically it is less surprising, when we bear in mind that, typically at inception, financing is not invested in innovation, but is invested in production. A loose coupling could also be caused by information asymmetry, where the entrepreneurs who have creative idea and innovation capability cannot be identified by the investors. Such interpretation can find some evidence in the study by Shu et al. (2018).

Alternatively, it could also be the entrepreneurs who have financing capability or financial resources lack the incentives, energy or capability to polish their ideas or projects but are eager to start the new ventures. These could be the so-called necessitydriven or desperate entrepreneurial activities, which are in contrast to opportunitydriven actions (Mühlböck et al. 2018; Fernández-Serrano et al. 2018). The study by Mühlböck et al. (2018), using the data from the Global Entrepreneurship Monitor (GEM), has provided some evidence. They observed that many entrepreneurs sprung up during the outbreak of the economic crisis, but these businesses were started even without (or with a negative) perception of business opportunities and entrepreneurial skills. The authors term this phenomenon as "nons-entrepreneurship" driven by necessity, meaning there are no other options for a job but only to start their own businesses. Usually in such cases, the institutional environment is favorable. Besides, according to their findings, there is a considerable share of such individuals among early stage entrepreneurs.

Additionally, we suspect that the coupling is very loose at the inception, because the competitive advantage of coupling has not yet taken effect at inception. The coupling will have an effect only later, we expect, namely as the startup competes in the market, for survival, expansion and growth. Therefore, coupling is appropriately considered strategic building of capabilities. Future research may advance our knowledge regarding such loose coupling.

From these findings, we may learn at least two practical lessons. First, financing and innovation do not go hand in hand at the inception, although this is actually important for a new venture to succeed. The failure rate of entrepreneurial firms is high mainly due to the resource scarcity and financial constrains (Colombo et al. 2014). Such loose coupling, as discussed above, could be caused by low participation willingness of the capital owners or a lack of effective channels for two sides to identify/know each other. Policymakers may give special attention to these, and design some mechanisms, set up the rules, or provide the supports to attract or guide the capital into the inception phase and reduce the potential problem of information asymmetry between two sides. Besides, with aforementioned potential reason of the presence of necessity-driven entrepreneurs that causes the loose coupling, both policymakers and investors are 
suggested to distinguish between the necessity- (especially desperate) and opportunitybased entrepreneurs and take actions. As considered by Mühlböck et al. (2018) and confirmed by Fernández-Serrano et al. (2018), those desperate or necessity-driven entrepreneurs with a lesser feasibility and skills may be less successful and thus less beneficial for the economy than opportunity-driven entrepreneurs.

Second, entrepreneurs, and especially nascent entrepreneurs, should pay attention to create such coupling, and networking can be an efficient way as will be discussed below. A recent study by RezaeiZadeh et al. (2017) found interpersonal skills for networking is one of the top competences that the entrepreneurs should possess, and they suggest such competence development be included in university education. Meanwhile, they suggest that continuous training programs with a network of proactive peers, engaged academics, and a wider business community will help sustain and develop entrepreneurial intentions and behaviors, as well as expand the entrepreneurs' networks. Below, we discuss the network influence in more detail.

\section{Coupling embedded in networks}

Coupling is channeled, enabled and constrained by networks around the entrepreneur. On a broader level, we may say networking capability is one of the important organizational capabilities, especially in the increasingly knowledge-intensive and turbulent economic environment, since different networks represent different conduits of information and resources that the organization can constantly access. Thereby, the organization can become more flexible and adaptive. As also advocated by Windsperger et al. (2018, p.671), entrepreneurial networks should be used by the firms "to complement their resources and capabilities in order to realize static and dynamic efficiency advantages".

Networking is typically thought of as inherently beneficial - the more, the merrier but some networking may be a waste of time and energy, and some networking may even be detrimental, so networking has its "dark side" (Klyver et al. 2011).

Networking in the private sphere was here found to be detrimental for coupling, as hypothesized. This finding is consistent with earlier studies, showing negative effects of networking in the private sphere upon outputs such as innovation, exporting, and expectation for growth of the business (Schøtt and Sedaghat 2014; Ashourizadeh and Schøtt 2015; Cheraghi et al. 2014). More generally, whereas networking in the private sphere is beneficial for legitimacy and emotional support (Liu et al. 2019), networking in the private sphere seems detrimental for outputs. Network research should not presume that a network is homogenous (as presumed in the most common measure of an actor's social capital as number of contacts), but should distinguish between the dark side and the bright side of a network (Klyver et al. 2011).

On the bright side, we found that an entrepreneur's networking in the public sphere - i.e. in the workplace, professions, market, and international environment - is beneficial for coupling between innovation and financing. Drawing advices from a wide spectrum in the public sphere, a wide spectrum of knowledgeable specialists (also apart from researchers and investors), enables the entrepreneur to combine various kinds of knowledge, information, and resources, which is beneficial for the simultaneous pursuits of innovation and financing. 
An entrepreneur's networking with a potential investor was also found to benefit the coupling between financing and innovation in the startup, as expected. As also expected, networking with a researcher benefits the coupling.

Over and above these two additive effects, coupling was found to be further enhanced by simultaneously networking with an investor and with a researcher, discerned as an interaction effect in a multivariate model. Networking with an investor and networking with a researcher are not substitutable for one another, and their effects do not simply add up. Rather, there is a synergy effect, a further enhancing effect over and above the two separate effects of networking with an investor and networking with a researcher.

The theory of competitive advantage through structural holes in the network around an actor can help us understanding the synergy benefit (Burt 1992a, b). A focal actor has a structural hole in the network of contacts, when two contacts are not interrelated. The hole between the two implies that they cannot combine something from one with another thing from the other. The focal actor, however, can acquire something from one and another thing from the other, and can thereby combine the two things and, following Schumpeterian thinking, the combination constitutes a competitive advantage in the competition among actors for new things. The literal meaning of 'entrepreneur' is going in between and taking a benefit, and in our study the entrepreneur is going between an investor and a researcher, and combining advice or investment from the former with advice or new idea from the latter, and thereby promotes a coupling of financing and innovation, a synergy that builds a capability and a competitive advantage.

From the resource-based view (Barney 1991; Grant 1991) and the dynamic capabilities perspective (Teece et al. 1997), a firm's resources and capabilities will determine its competitive advantage and value creation, and a firm needs to constantly adapt, renew, reconfigure and re-create its resources and capabilities to the volatile and competitive environment, so that a competitive advantage can be developed and maintained. However, the entrepreneurial firms, especially those at formation stage run by nascent entrepreneurs, usually lack the strategic resources and capabilities at the beginning, e.g., financial resources and financing capabilities, innovation resources and capabilities, business management skills, and have lesser competitive disadvantages. Furthermore, the emergence and development of a new venture is a dynamic process with many uncertainties, requiring different resources, information, and knowledge at different time points (Hayter 2016; Steier and Greenwood 2000).

Different relationship networks, especially the professional ones discussed in this study, can provide new ventures with opportunities for continually accessing needed resources, forming a basis that enables coupling of financing and innovation, synergy creation from integrating various resources, develop and sustain the new venture's competitive advantages, and gain profit (see also Davidsson and Honig 2003; Batjargal and Liu 2004). Along the same lines, holding a relational governance view of competitive advantage, Dyer and Singh (1998) argue for the critical resources that enable the firm's competitive advantage to extend beyond firm boundaries and are embedded in inter-firm resources and routines, including such components as relation-specific assets, knowledge-sharing routines and complementary resources/capabilities. In summary, we may say networking and coupling capabilities are two crucial capabilities for the nascent entrepreneurs, on top of the others, for identifying, pursuing and creating 
market opportunities, and for attaining and sustaining the new ventures' competitive advantages.

Joining the discussion of the influence of strong vs. weak ties (or private vs. public networks) on the entrepreneurs, results of this study, falling in line with some of the research (Granovetter 1973; Davidsson and Honig 2003; Afandi et al. 2017), further remind the entrepreneurs to be aware of potential detrimental effect of being overembedded in the private sphere network that is bringing information and resource redundancy and social obligation. Rather, they are well advised to actively and judiciously pursue, develop, and maintain public sphere networking, especially the professional networks with the investors and researchers/inventors, which enable and promote the coupling between innovation and financing, and capability development in these regards.

The entrepreneur network capability framework developed by Shu et al. (2018) can be a good reference, four dimensions comprising network orientation, network building, network maintenance, and network coordination. Network orientation should be in the first place, which means a person should be willing to develop and depend on social networks in own daily socialization, believe, pay special attention to and act on the norms of dependence, cooperation, and reciprocation. In terms of the orientation, as discussed, this study suggests the importance and benefits of widening and diversifying the entrepreneurs' social relations, especially being in and crossing different professional communities. However, most of the entrepreneurs may be not aware of this. For instance, a study of university spin-off by Hayter (2016) found that early-stage academic entrepreneurs have their contacts mainly within academic communities that are typically located in their home institutions, and such homophilous ties would further constrain the entrepreneurial development.

With clear orientation, the entrepreneur shall monitor surroundings and make effective investment to establish and expand the networks. However, as reminded by Semrau and Werner (2012), it is not a good idea to extend the network size without boundaries because there is an opportunity cost of time and the cost can surpass the benefits that the networks can bring. Our study further suggests that it is worthwhile to invest in developing the contacts at least in two communities, i.e., with capital holders and knowledgeable and new ideas generators, due to the unique and mutual-reinforced synergistic contributions to founding the new venture, as discussed earlier. It can happen that the nascent entrepreneurs have sufficient personal or family wealth to self-finance the start-up process. However, the entrepreneurs ought to remember that sometimes it is not the "capital" itself that makes the success of a new venture, but the capital-associated resources that help, i.e., from the sources providing capital. . The entrepreneurs ought to think about the other benefits that the investors could bring, such as commercialization competences, business management skills, reputation, more diverse network access, synergistic effect, as shown in several studies (Van Osnabrugge and Robinson 2000; Hsu 2004; Mason and Stark 2004; Croce et al. 2017). Further, while network maintenance is to ensure stable and long-term exchange relationships with them, network cooperation is to manage multiple and dynamic relationships, and to mobilize and integrate resources.

Moreover, these results may also be relevant for well-established organizations that seek to enhance their innovation and financing capabilities and gain a competitive advantage, suggesting that strategically developing, managing and utilizing the 
bridging social ties may be an efficient way. At the individual level, this may encompass designing an incentive scheme and training program to improve the employees' entrepreneurial spirit, networking awareness and capability. At the organizational level, the firms should strategically manage inter-organizational relationships, both formal and informal, and build systems that can monitor the surroundings, and thereby identify and evaluate new business opportunities outside the organizational boundaries. Relevant concepts, models and strategies can be, e.g., cooperative entrepreneurship (Rezazadeh \& Nobari, 2018) and open innovation (Enkel et al. 2009). As concluded by Rezazadeh and Nobari (2018), cooperative entrepreneurship is likely to lead to improvement of firms' agility, customer relationship management, learning, innovation, and sensing capabilities.

From a public policy perspective, the above results have important policy implications, stemming essentially from the contribution to innovation coming from networking with researchers, inventors and investors. If innovation and entrepreneurial businesses are important for economic development and for people's life, the study clearly suggests that public policy should be designed to encourage, facilitate and support business networking activities, researcher-business collaboration, and investorentrepreneur connections. Besides, university education should be another focus by the policy-makers, since it can be an efficient way or a starting point to foster people's entrepreneurial spirits, develop the students' entrepreneurial competences, especially their networking and relationship management capabilities, and even provide some opportunities for them to develop their networks which may enable them to be an entrepreneur in the future. Some strategies and models can be, as documented, the university-based incubation programs, entrepreneurship education programs, researchbased spin-off, and building entrepreneurial universities (Clarysse and Moray 2004; Rothaermel et al. 2007; Budyldina 2018).

\section{Limitations}

Our research design was to investigate coupling at inception of the startup. This design has the advantages of avoiding attrition when startups are abandoned and avoiding retrospection if interviews were to be conducted later. But the cross-sectional focus on inception implies that the fate of a startup and its coupling are unknown. Coupling is presumably yielding a competitive advantage, but at inception this is not enacted. Another limitation is that the data are from around 2014, so we have observed the same constraints confronted by other scholars of entrepreneur and entrepreneurship (e.g., Mühlböck et al. 2018; Fernández-Serrano et al. 2018). Entrepreneurial behavior has changed since networking was surveyed by GEM, and organizing is changing even more with the COVID-19 pandemic.

\section{Further research}

The limitations suggest further research on coupling. Coupling appears important as a strategy for building capability and competitive advantage. Therefore, an important research question is, what is the effect of coupling in a startup upon its ability to compete, survive, expand and grow? An indication of the effect of coupling upon growth was seen in the substantial correlation between coupling and expectation for 
growth of the business (section 3.2.3). But, of course, effects of coupling are far better ascertained through longitudinal research.

The current COVID-19 pandemic is an eco-systemic intervention that is changing competition and organizational behavior. Based on our findings, we hypothesize current exits to be especially prevalent among entrepreneurs without coupling of financing and innovation, and we hypothesize that success is especially likely for entrepreneurs with a tight coupling between innovation and financing. Such hypotheses may well be tested with some of the surveys that are underway in the wake of the pandemic.

\section{References}

Adomako, S., Danso, A., Boso, N., \& Narteh, B. (2018). Entrepreneurial alertness and new venture performance: facilitating roles of networking capability. International Small Business Journal, 0266242617747667.

Afandi, E., Kermani, M., \& Mammadov, F. (2017). Social capital and entrepreneurial process. International Entrepreneurship and Management Journal, 13(3), 685-716.

Anderson, A. R., Jack, S. L., \& Dodd, S. D. (2005). The role of family members in entrepreneurial networks: Beyond the boundaries of the family firm. Family Business Review, 18(2), 135-154.

Ansoff, H. I. (1987). The emerging paradigm of strategic behavior. Strategic management journal, 8(6), 501515.

Ashourizadeh, S., \& Schøtt, T. (2015). Exporting embedded in culture and transnational networks around entrepreneurs. International Journal of Business and Globalisation, 16(3), 314-334.

Barney, J. (1991). Firm resources and sustained competitive advantage. Journal of Management, 17(1), 99120.

Batjargal, B., \& Liu, M. (2004). Entrepreneurs' access to private equity in China: the role of social capital. Organization Science, 15(2), 159-172.

Bertoni, F., Croce, A., \& D'Adda, D. (2010). Venture capital investments and patenting activity of high-tech start-ups: a micro-econometric firm-level analysis. Venture Capital, 12(4), 307-326.

Bosma, N. (2013). The global entrepreneurship monitor (GEM) and its impact on entrepreneurship research. Foundations and Trends in Entrepreneurship, 9(2), 143-248.

Boyd, N. G., \& Vozikis, G. S. (1994). The influence of self-efficacy on the development of entrepreneurial intentions and actions. Entrepreneurship Theory and Practice, 18(4), 63-77.

Brown, R., Mawson, S., Rowe, A., \& Mason, C. (2018). Working the crowd: Improvisational entrepreneurship and equity crowdfunding in nascent entrepreneurial ventures. International Small Business Journal, 36(2), 169-193.

Budyldina, N. (2018). Entrepreneurial universities and regional contribution. International Entrepreneurship and Management Journal, 14(2), 265-277.

Burt, R. S. (1992a). Structural holes. Cambridge: Harvard University Press.

Burt, R. S. (1992b). The social structure of competition. In N. Nohria \& R. G. Eccles (Eds.), Networks and organizations: Structure, form and action. Boston: Harvard Business School Press.

Burt, R. S. (2004). Structural holes and good ideas. American Journal of Sociology, 110(2), 349-399.

Calia, R. C., Guerrini, F. M., \& Moura, G. L. (2007). Innovation networks: from technological development to business model reconfiguration. Technovation, 27(8), 426-432.

Cheraghi, M., Setti, Z., \& Schøtt, T. (2014). Growth-expectations among women entrepreneurs: embedded in networks and culture in Algeria, Morocco, Tunisia and in Belgium and France. International Journal of Entrepreneurship and Small Business, 23(1-2), 191-212.

Clarysse, B., \& Moray, N. (2004). A process study of entrepreneurial team formation: the case of a researchbased spin-off. Journal of Business Venturing, 19(1), 55-79.

Colombelli, A., \& Quatraro, F. (2017). Green start-ups and local knowledge spillovers from clean and dirty technologies. Small Business Economics, 1-20.

Colombelli, A., Krafft, J., \& Vivarelli, M. (2016). To be born is not enough: the key role of innovative startups. Small Business Economics, 47(2), 277-291. 
Colombo, M. G., Croce, A., \& Murtinu, S. (2014). Ownership structure, horizontal agency costs and the performance of high-tech entrepreneurial firms. Small Business Economics, 42(2), 265-282.

Cooper, S. Y., \& Park, J. S. (2008). The impact of incubator' organizations on opportunity recognition and technology innovation in new, entrepreneurial high-technology ventures. International Small Business Journal, 26(1), 27-56.

Croce, A., Tenca, F., \& Ughetto, E. (2017). How business angel groups work: rejection criteria in investment evaluation. International Small Business Journal, 35(4), 405-426.

Davidsson, P., \& Honig, B. (2003). The role of social and human capital among nascent entrepreneurs. Journal of Business Venturing, 18(3), 301-331.

De Bettignies, J. E., \& Brander, J. A. (2007). Financing entrepreneurship: bank finance versus venture capital. Journal of Business Venturing, 22(6), 808-832.

Dyer, J. H., \& Singh, H. (1998). The relational view: cooperative strategy and sources of interorganizational competitive advantage. Academy of Management Review, 23(4), 660-679.

Dyer, J. H., Gregersen, H. B., \& Christensen, C. (2008). Entrepreneur behaviors, opportunity recognition, and the origins of innovative ventures. Strategic Entrepreneurship Journal, 2(4), 317-338.

Ebbers, J. J. (2014). Networking behavior and contracting relationships among entrepreneurs in business incubators. Entrepreneurship Theory and Practice, 38(5), 1-23.

Engel, D., \& Keilbach, M. (2007). Firm-level implications of early stage venture capital investment - an empirical investigation. Journal of Empirical Finance, 14(2), 150-167.

Enkel, E., Gassmann, O., \& Chesbrough, H. (2009). Open R\&D and open innovation: exploring the phenomenon. R\&D Management, 39(4), 311-316.

Etzkowitz, H. (2003). Innovation in innovation: the triple helix of university-industry-government relations. Social Science Information, 42(3), 293-337.

Fernández-Serrano, J., Berbegal, V., Velasco, F., \& Expósito, A. (2018). Efficient entrepreneurial culture: a cross-country analysis of developed countries. International Entrepreneurship and Management Journal, 14(1), 105-127.

Granovetter, M. S. (1973). The strength of weak ties. American Journal of Sociology, 78, 1360-1380.

Granovetter, M. (1985). Economic action and social structure: the problem of embeddedness. American Journal of Sociology, 91, 481-510.

Grant, R. M. (1991). The resource-based theory of competitive advantage: implications for strategy formulation. California Management Review, 33(3), 114-135.

Greve, A. (1995). Networks and entrepreneurship - an analysis of social relations, occupational background, and use of contacts during the establishment process. Scandinavian Journal of Management, 11(1), 1-24.

Hayter, C. S. (2016). Constraining entrepreneurial development: a knowledge-based view of social networks among academic entrepreneurs. Research Policy, 45(2), 475-490.

Hsu, D. H. (2004). What do entrepreneurs pay for venture capital affiliation? The Journal of Finance, 59(4), 1805-1844.

Hsu, C. W. (2005). Formation of industrial innovation mechanisms through the research institute. Technovation, 25(11), 1317-1329.

Jensen, M. C., \& Meckling, W. H. (1976). Theory of the firm: managerial behavior, agency costs and ownership structure. Journal of Financial Economics, 3(4), 305-360.

Jensen, K.W., \& Schøtt, T. (2017). Components of the network around an actor. Encyclopedia of Social Network Analysis and Mining, Vol 1, 2nd ed, by Reda Alhajj \& Jon Rokne. New York: Springer Science and Business Media. https://doi.org/10.1007/978-1-4614-7163-9_366-1.

Kaplan, S. N., \& Strömberg, P. E. (2004). Characteristics, contracts, and actions: evidence from venture capitalist analyses. The Journal of Finance, 59(5), 2177-2210.

Klyver, K., Evald, M. R., \& Hindle, K. (2011). Social networks and new venture creation: The dark side of networks. In K. Hindle \& K. Klyver (Eds.), Handbook of research on new venture creation (pp. 145159). Cheltenham: Edward Elgar Publishing.

Kortum, S., \& Lerner, J. (2000). Assessing the contribution of venture capital to innovation. RAND Journal of Economics, 31, 674-692.

Lichtenstein, B. B., Dooley, K. J., \& Lumpkin, G. T. (2006). Measuring emergence in the dynamics of new venture creation. Journal of Business Venturing, 21(2), 153-175.

Liñán, F., \& Chen, Y. W. (2009). Development and cross-cultural application of a specific instrument to measure entrepreneurial intentions. Entrepreneurship theory and practice, 33(3), 593-617.

Liu, Y., Schøtt, T., \& Zhang, C. (2019). Women's experiences of legitimacy, satisfaction and commitment as entrepreneurs: embedded in gender hierarchy and networks in private and business spheres. Entrepreneurship \& Regional Development. (in press), 31, 293-307. 
Löfsten, H., \& Lindelöf, P. (2005). R\&D networks and product innovation patterns - academic and nonacademic new technology-based firms on science parks. Technovation, 25(9), 1025-1037.

Mason, C., \& Stark, M. (2004). What do investors look for in a business plan? A comparison of the investment criteria of bankers, venture capitalists and business angels. International Small Business Journal, 22(3), 227-248.

McCann, B. T., \& Vroom, G. (2015). Opportunity evaluation and changing beliefs during the nascent entrepreneurial process. International Small Business Journal, 33(6), 612-637.

Mühlböck, M., Warmuth, J. R., Holienka, M., \& Kittel, B. (2018). Desperate entrepreneurs: no opportunities, no skills. International Entrepreneurship and Management Journal, 14(4), 975-997.

Murray, F. (2004). The role of academic inventors in entrepreneurial firms: sharing the laboratory life. Research Policy, 33(4), 643-659.

Orton, J. D., \& Weick, K. E. (1990). Loosely coupled systems: a reconceptualization. Academy of Management Review, 15(2), 203-223.

Ramos-Rodríguez, A. R., Medina-Garrido, J. A., Lorenzo-Gómez, J. D., \& Ruiz-Navarro, J. (2010). What you know or who you know? The role of intellectual and social capital in opportunity recognition. International Small Business Journal, 28(6), 566-582.

RezaeiZadeh, M., Hogan, M., O’Reilly, J., Cunningham, J., \& Murphy, E. (2017). Core entrepreneurial competencies and their interdependencies: insights from a study of Irish and Iranian entrepreneurs, university students and academics. International Entrepreneurship and Management Journal, 13(1), 35-73.

Rezazadeh, A., \& Nobari, N. (2018). Antecedents and consequences of cooperative entrepreneurship: A conceptual model and empirical investigation. International Entrepreneurship and Management Journal, 14(2), 479-507.

Rothaermel, F. T., Agung, S. D., \& Jiang, L. (2007). University entrepreneurship: a taxonomy of the literature. Industrial and Corporate Change, 16(4), 691-791.

Sapienza, H. J., \& De Clercq, D. (2000). Venture capitalist-entrepreneur relationships in technology-based ventures. Enterprise and Innovation Management Studies, 1(1), 57-71.

Schøtt, T., \& Cheraghi, M. (2015). Gendering pursuits of innovation: embeddedness in networks and culture. International Journal of Entrepreneurship and Small Business, 24(1), 83-116.

Schøtt, T., \& Sedaghat, M. (2014). Innovation embedded in entrepreneurs' networks and national educational systems: a global study. Small Business Economics, 43(2), 463-476.

Semrau, T., \& Werner, A. (2012). The two sides of the story: network investments and new venture creation. Journal of Small Business Management, 50(1), 159-180.

Shu, R., Ren, S., \& Zheng, Y. (2018). Building networks into discovery: the link between entrepreneur network capability and entrepreneurial opportunity discovery. Journal of Business Research, 85, 197208.

Snijders, T. A. B., \& Bosker, R. J. (2012). Multilevel analysis: An introduction to basic and advanced multilevel modeling. Thousand Oaks: Sage.

Steier, L., \& Greenwood, R. (2000). Entrepreneurship and the evolution of angel financial networks. Organization Studies, 21(1), 163-192.

Teece, D. J., Pisano, G., \& Shuen, A. (1997). Dynamic capabilities and strategic management. Strategic Management Journal, 18, 509-533.

Timmons, J. A., \& Bygrave, W. D. (1986). Venture capital's role in financing innovation for economic growth. Journal of Business Venturing, 1(2), 161-176.

Van Osnabrugge, M., \& Robinson, R. J. (2000). Angel investing: Matching startup funds with startup companies-the guide for entrepreneurs and individual investors. Wiley.

Weiblen, T., \& Chesbrough, H. W. (2015). Engaging with startups to enhance corporate innovation. California Management Review, 57(2), 66-90.

Weick, K. E. (1976). Educational organizations as loosely coupled systems. Administrative Science Quarterly, $1-19$.

Windsperger, J., Hendrikse, G. W., Cliquet, G., \& Ehrmann, T. (2018). Governance and strategy of entrepreneurial networks: an introduction. Small Business Economics, 50(4), 671-676.

Wong, A., Bhatia, M., \& Freeman, Z. (2009). Angel finance: the other venture capital. Strategic Change, 18(7-8), 221-230.

Wood, R., \& Bandura, A. (1989). Social cognitive theory of organizational management. Academy of Management Review, 14(3), 361-384.

Publisher's note Springer Nature remains neutral with regard to jurisdictional claims in published maps and institutional affiliations. 